\title{
Lumbar Stenosis: Analysis of Factors Affecting Outcome in 81 Surigical Cases
}

BRYCE WEIR and ROBERTO DE LEO

SUMMARY: The authors report on a retrospective analysis of 81 patients undergoing laminectomy for the clinico-radiological diagnosis of lumbar stenosis. One hundred and eighty-five variables were considered and a computer system was used in their evaluation.

The most frequent site of involvement was at L4-5. Follow-up time ranged from 3 months to 12 years. $95 \%$ good results were obtained, and the re-operation rate was $7 \%$.

RESUME: Les auteurs présentent une analyse rétrospective de 81 patients subissant une laminectomie pour le diagnostique clinique et radiologique de sténose lombaire. Cent quatre-vingt-cinq variations furent considérées et un ordinateur fut utilisé dans leurs évaluations.

Le plus fréquent lieu d'implication fut à L4-5. Les visites subséquentes s'étendent de 3 mois à 12 années. De bons résultats furent obtenus à $95 \%$ et le taux d'une ré-opération fut $7 \%$.
The complication rate was $11 \%$. There was no mortality. No significant correlation between factors investigated and the outcome was found.

This is in contrast to our series of lumbosacral disc protrusions in which factors such as duration of symptoms and the presence of compensation indicated a poor outcome.

Results are compared with other series.

Le taux de complications fut $11 \%$. Il n'y a pas eu de mortalité. Aucune corrélation d'importance entre les facteurs étudiés et le résultat fut trouvée. Ceci diffère de nos séries d'hernies discales sacro-lombaires dans lesquelles les facteurs, comme la durée de symptômes et la présence de compensation indiquaient un résultat médiocre.

Les résultats sont comparés à d'autres séries.

\section{INTRODUCTION}

The lumbo-sacral nerve roots can be compressed by three principal mechanisms: simple disc protrusion, spondylosis, resulting from over-growth of facets, laminae or vertebral bodies, and stenosis, involving all the spinal bony elements. Disc protrusions and spondylosis are usually symptomatic at only one level; in stenosis there is developmental narrowing of the spinal canal over one or more segments. Consequently, even minor hypertrophic changes in the vertebral bodies or ligamenta flava can seriously compromise the neural elements. The term stenosis is used to refer to the multiple processes other than simple disc protrusion which can compromise lumbosacral nerve roots. Included in this category are cases of spondylosis unassociated with disc protrusion.

The importance of non-disc mechanical compression of the neural elements in the lumbo-sacral canal was established early in this century by Bailey and Casamajor (1911), who demonstrated that osteoarthritis could cause neural compression. The meticulous series of investigations carried out by Verbeist (1954) led to a better understanding of this important cause of root compression. In a series of 97 patients with spinal stenosis, neurogenic intermittent claudication occurred in $72 \%$ (Verbiest, 1976). The radiating leg pain in this disorder can be related to either exertion or posture. Dysesthesia and "sensory march" are more common than in arterial claudication. Other symptoms of stenosis of the lumbar canal include back pain, sciatica, sensory, reflex and motor deficits, and sphincter dysfunction. Narrowing of the spinal canal is a feature of achondroplastic dwarfism, osteochondrodystrophy and gargoyl-
From the Division of Neurosurgery, University of Alberta, Edmonton, Alberta, Canada.

Reprint requests to Dr. Bryce Weir, 520, 8409 - 112 Street, Edmonton, Alberta, T6G 1K6, Canada. 


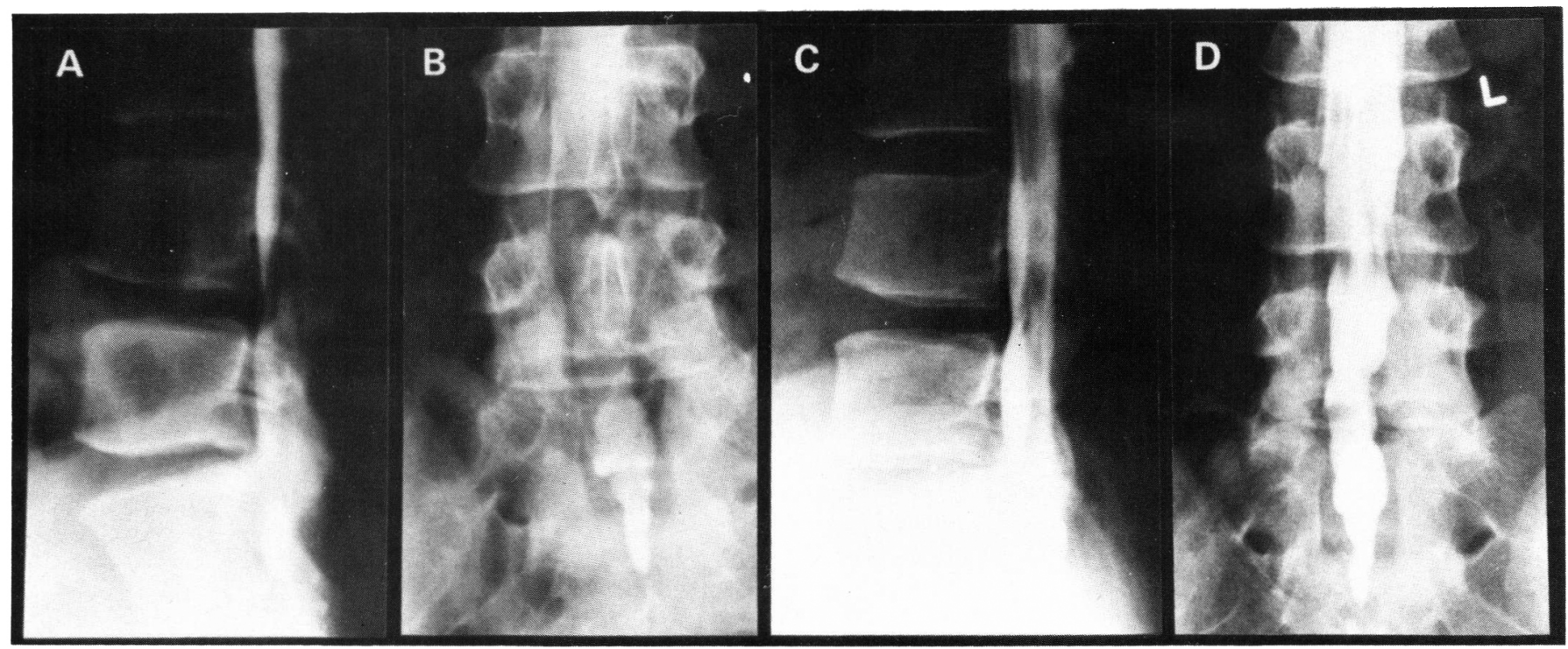

Figure 1-28 year female had lumbo-sacral discectomy 3 years prior to this myelogram (A and B) at another hospital without significant relief. She is seen to have a very narrow lumbar theca. She presented with paraparesis, sphincter involvement and was bed-ridden with pain. Post-operative myelogram (C and D) shows "enlargement" of the dural tube. There was dramatic clinical improvement. She had L4 and 5 laminectomy, facets were left intact.
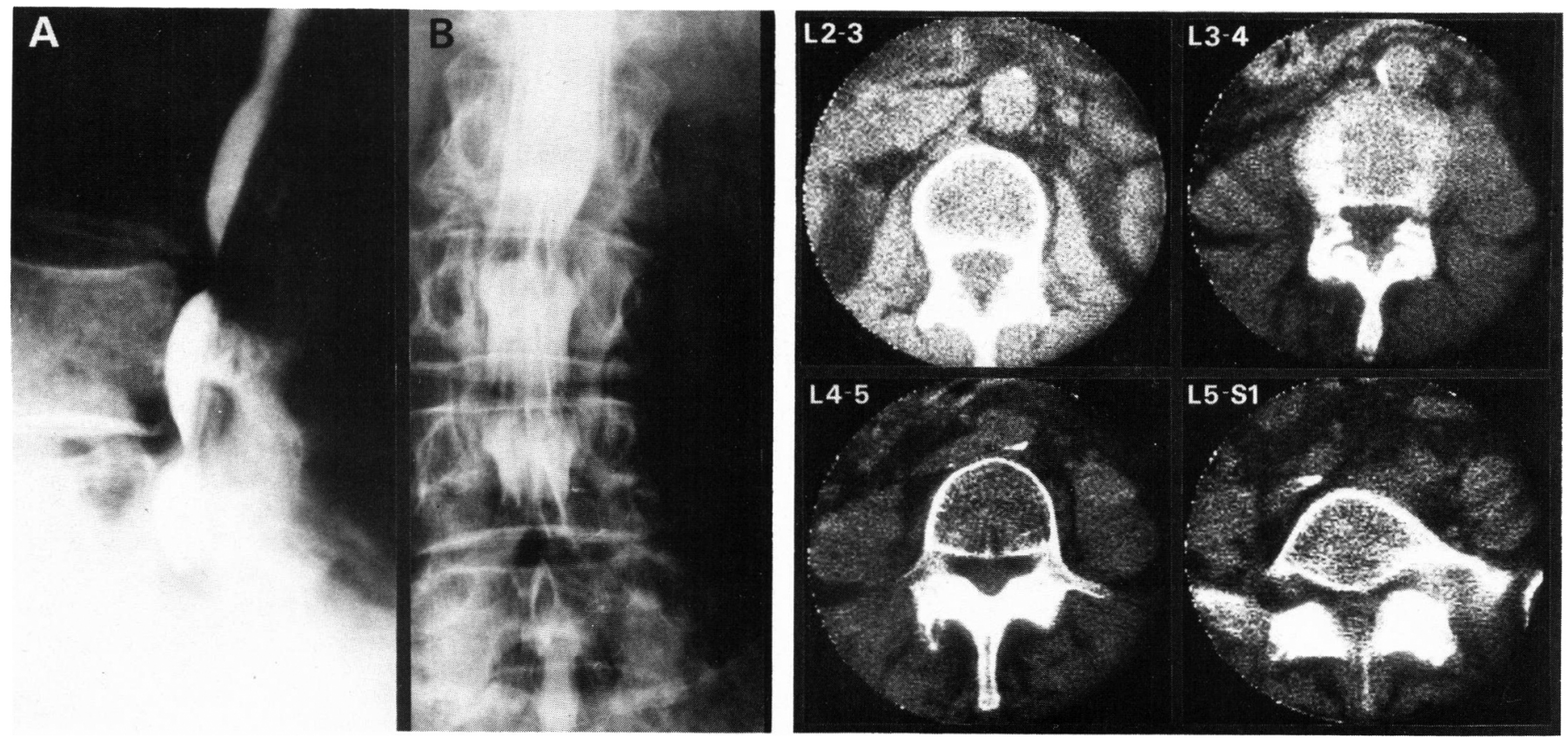

Figure 2-Myelogram corresponding to the CAT scan in Figure 3. Figure 3-CAT scans at various levels show extensive degenerative This 65 year female had typical neurogenic claudication and diffuse changes at the L4-5 and L5-S, apophyseal joints with encroachment dysesthesiae in her legs as well as mild bilateral weakness. Immedi- on the canal. ately following laminectomy of L3-4-5 her legs felt normal.

ism. More commonly the narrowed spinal canal is a developmental abnormality which is not the result of a specific inherited disorder. It can also be acquired as the result of trauma and surgery.
Accurate diagnosis of lumbar spinal stenosis and its surgical treatment by laminectomy did not occur with any regularity until the 1960's (Cauchoix et al, 1980; Epstein et al, 1962; Weinstein et al, 1977).
The diagnosis of lumbar stenosis is made on the basis of clinical history with radiologic confirmation. Distances smaller than $17 \mathrm{~mm}$. at the interpedicular level or $12 \mathrm{~mm}$. at the mid-sagittal diameter should suggest 
the possibility of lumbar stenosis. Verbeist defines a relative stenosis as an anterior-posterior diameter under $12 \mathrm{~mm}$. and an absolute stenosis as one less than $10 \mathrm{~mm}$. anywhere in the lumbar canal. A myelographic picture is characteristic (Fig. 1 and 2). Computerized axial tomography of the lumbar spine (Fig. 3) now permits more precise delineation of the various pathologic factors and will probably become the method of choice for diagnosing spinal stenosis. With our present generation of CT scanner however, we still consider myelography an indispensable part of the investigation.

The only effective treatment is surgical and is aimed at decompressing the lumbo-sacral roots within and where they emerge from the dural sac. Our operative technique has been to remove one or two laminae, usually bilaterally. We attempt to preserve the facets although partial removal of the mesial aspect of the superior facet of the inferior vertebra may be necessary. Removal of osteophytes anteriorly may be required for adequate decompression of the nerve roots but we believe that most can be safely left alone unless they are of extreme size. The older the patient, the more florid the degenerative bony changes and the more rostrally they occur, the more likely it is that simple discectomy will not produce adequate relief. Discs should not be removed unless there is clear extrusion or sequestration, since performing a discectomy adds to the risk of iatrogenic damage to the nerve roots and later perineural fibrosis, when lumbar stenosis is present.

In elderly patients bed-ridden with agonizing pain, sphincter involvement, and paraparesis; laminectomy will provide relief with very little risk.

TABLE 1

Outcome Following Surgery on 81 Patients With Lumbar Stenosis

\begin{tabular}{|lr|}
\hline Cured & $21 \%$ \\
Better & $74 \%$ \\
Unchanged & $3 \%$ \\
Worse & $1 \%$ \\
Not known & $1 \%$ \\
\hline
\end{tabular}

\section{MATERIALS AND METHODS}

The records of eighty-one patients who had a clinical-radiological diagnosis of lumbar stenosis were reviewed. One hundred and eighty-five variables were recorded and a computer system used for their analysis.

\section{RESULTS}

95\% of the patients consider that they were cured or better following the surgery (Table 1).

$30 \%$ of the patients were females and $70 \%$ were males. The patients tended to be older than those with simple disc protrusions, $64 \%$ being over 50 (Table $2)$. In this older age group associated medical illnesses were common. $23 \%$ had cardiopulmonary disease, $6 \%$ severe obesity and $3 \%$ a history of cancer. On admission to hospital $57 \%$ were on narcotics, $4 \%$ steroids, $1 \%$ antibiotics and $7 \%$ on diuretics or cardiovascular drugs. $27 \%$ of the patients were on Workers' Compensation, $73 \%$ were not. $15 \%$ of the patients entered hospital on a stretcher or wheelchair, unable to walk. $83 \%$ had an abnormal neurologic examination. The most common findings were depression of deep tendon jerks and weakness.

The average duration of anesthesia was $1.7 \pm .08$ hours. $93 \%$ of the operations were carried out in under 3 hours of anesthesia. $12 \%$ of the patients received blood transfusions but only $2 \%$ required more than one unit.

The level of involvement tended to be more rostral than that for the usual level of disc protrusions (Table 3).

TABLE 2

Age Distribution of Patients With Lumbar Stenosis

\begin{tabular}{|cc|}
\multicolumn{1}{c|}{ Age } & Percentage \\
\hline$<30$ & $2 \%$ \\
$31-40$ & $17 \%$ \\
$41-50$ & $17 \%$ \\
$51-60$ & $33 \%$ \\
$61-70$ & $24 \%$ \\
$71-80$ & $6 \%$ \\
$>80$ & $1 \%$ \\
\hline
\end{tabular}

Only $14 \%$ had maximum compression at $\mathrm{L} 5-\mathrm{S} 1$ whereas $32 \%$ had maximum compression at L3-4 or higher.

One patient had a post-operative infection and another had a permanent increase in neurological deficit (there was a moderate increase in bilateral leg weakness in a male). Other postoperative complications are listed in Table 4. The average duration of postoperative hospital stay was $10.5 \pm .7$ days (Table 5).

TABLE 3

Principal Level of Involvement

\begin{tabular}{|lc|}
\hline L1-2 & $4 \%$ \\
L2-3 & $4 \%$ \\
L3-4 & $25 \%$ \\
L4-5 & $53 \%$ \\
L.5-S1 & $14 \%$ \\
L5-6 & $1 \%$ \\
\hline
\end{tabular}

Table 4

Post-Operative Complications

\begin{tabular}{|lc|}
\hline \multicolumn{1}{|c}{ Complication } & $\begin{array}{c}\text { No. of } \\
\text { Patients } \\
(\%)\end{array}$ \\
\cline { 2 - 3 } Transient Neurological Deficit & $3(4)$ \\
Post-Operative Infection & $1(1)$ \\
Genito-Urinary Symptoms & $2(3)$ \\
Pulmonary Complications & $2(3)$ \\
Permanently Increased & \\
Neurological Deficit & $1(1)$ \\
\hline
\end{tabular}

TABLE 5

Duration of Post-Operative Hospital Stay

No. days $\%$ of patients

$<7$ days

$33 \%$

8-14 days

$51 \%$

15-21 days

$7 \%$

$>21$ days

$9 \%$ 
The time to followup has ranged from 3 months to 12 years. $7 \%$ of patients have been re-operated; $2 \%$ within less than 12 months, $2 \%$ at less than 36 months and $1 \%$ at more than 37 months. $30 \%$ of patients made some subsequent medical contact for recurring symptoms which did not require surgery. The intervals between surgery and recurrence of symptoms was under one year in $23 \%$, three years in $4 \%$ and longer in $3 \%$. The vast majority of these were not nearly so severe as the pre-operative symptoms.

The data were analyzed in an attempt to identify factors which might be associated with an unfavorable outcome i.e., recurrence of symptoms or requirement for a second operation. No significant correlation was found between the outcome and age, sex, compensation status, year of surgery or number of days in hospital post-operatively. The total complication rate was $11 \%$ and this included patients who had transient increase in numbness or weakness, one patient with a superficial wound infection, patients requiring post-operative catheterization and cases with pulmonary atelectasis or pneumonia. It should be stressed that there were no deaths, no post-operative pulmonary embolism or thrombophlebitis, no deep infection and only one case of permanently increased neurological deficit.

\section{DISCUSSION}

In comparison to our series of discectomy patients (Weir and Jacobs, 1980) this group was older and had much more multi-level pathology and serious associated disease. Despite this, they did not have a higher complication rate and actually had a lower re-operation rate.

Table 6 compares our results with those of other published reports. While the exact criteria by which evaluation was carried out varied from series to series, the outcome in this complex disorder in all patients seems surprisingly good. We have defined a good result as being all those who were not classed as being the same or worse following surgery. Based on the data presented in Table 6 it appears that fewer than one patient in five would consider themselves unimproved by decompressive laminectomy.

Advanced age should not be considered a contraindication to the operation nor should associated medical disease. In our experience these patients are unlikely to improve spontaneously. Almost all of them reported having been placed on a trial of exercises or physiotherapy and these maneuvers only prolonged their period of suffering prior to surgery. Treating an elderly patient with bowel and bladder involvement or paraparesis with bedrest and analgesics is actually more radical therapy than surgery. The risk of deep vein thrombosis and pulmonary embolism is probably greater on prolonged bedrest than with decompressive laminectomy and early ambulation.

We feel that our relatively conservative approach to facetectomy, foramenectomy or resection of anterior osteophytes is justified by our results. We have not seen any late progressive instability develop and most patients

TABLE 6

Results of Surgery in Previously

Published Series of Patients With

Lumbar Stenosis

\begin{tabular}{|lcc|}
\hline & No. of patients & \% Good Results \\
Cauchoix, 1980 & 83 & $82 \%$ \\
Epstein, 1962 & 29 & $80 \%$ \\
Verbiest, 1976 & 97 & $84 \%$ \\
Weinstein, 1977 & 72 & $86 \%$ \\
Weir and de Leo & 81 & $95 \%$ \\
(present series) & & \\
\hline
\end{tabular}

seem to recover with the relatively limited laminectomy.

Clinicians should have a high index of suspicion when confronted with an elderly patient incapacitated by back and leg pain. If their painful numbness and tingling is worsened by the lordotic position or exertion, the possibility of lumbar stenosis should come to mind. The objective neurologic deficit may be mild and straight leg raising may be normal. If the patient is truly incapacitated however, radiologic investigation is warranted. Plain films may well suggest the diagnosis which can be confirmed by myelography and CT scans. We can now achieve a very accurate evaluation of the anatomical basis for the symptoms in patients with spinal stenosis. Surgical decompression can correct the specific pathology.

\section{REFERENCES}

BAILEY, P., CASAMAJOR, L. (1911). Osteoarthritis of the spine as a cause of compression of the spinal cord and its roots: with report of 5 cases. J. Nerv. Ment. Dis. 38, 588-609.

CAUCHOIX, J,, CHASSAING, V., BENOIST, M., BRIARD, J.L. (1980). Lumbar spinal stenosis in Wackenheim, A., Babin, E. Ed The Narrow Lumbar Canal. Radiological Signs and Surgery. Springer - Verlag, Berlin, Heidelberg, New York, pp. 170.

EPSTEIN, J.A., EPSTEIN, B.S., LEVINE, L.S. (1962). Nerve root compression associated with narrowing of the lumbar spinal canal. $\mathrm{J}$. Neurol. Neurosurg. Psychiat. 25, 165-176.

VERBIEST, H. (1954). Radicular syndrome from developmental narrowing of the lumbar vertebral canal. J. Bone. Joint. Surg. 36B, 230-237.

VERBEIST, H. (1976). Neurogenic intermittent claudication - lesions of the spinal cord and cauda equina, stenosis of the vertebral canal, narrowing of intervertebral foramina and entrapment of peripheral nerves. Ch. 19 in Tumours of the spine and spinal cord, Part II; Handbook of Clinical Neurology, Vol. 20, Vinken, P.J., Bruyn, G.W., eds. American Elsevier Publishing Co., Inc. New York, pp. 859.

WEINSTEIN, P.R., EHNI, G., WILSON, C.B Lumbar Spondylosis. (1977). Diagnosis, Management and Surgical Treatment. Year Book Medical Publisher, Chicago, pp. 203.

WEIR, B.K.A., JACOBS, G.A. (1980). Reoperation rate following lumbar discectomies. An analysis of 662 lumbar discectomies. Spine 5, 366-370. 